УДК 372.862

ПРИМЕНЕНИЕ ПРОЕКТНОГО ПОДХОДА ПРИ РЕАЛИЗАЦИИ ОБРАЗОВАТЕЛЬНОЙ ДИСЦИПЛИНЫ «МУЛЬТИМЕДИАТЕХНОЛОГИИ»

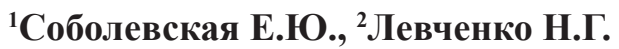 \\ ${ }^{\prime}$ ФГБОУ ВО «Владивостокский государственный университет экономики и сервиса», \\ Владивосток, e-mail: study_z@list.ru; \\ ${ }^{2}$ ФББОУ ВПО «Морской государственный университет им. адм. Г.И. Невельского», \\ Владивосток, е-mail: levchenko@msub.ru
}

\begin{abstract}
В статье рассматривается применение проектного подхода как доминирующей стратегии обучения при реализации образовательной дисциплины «Мультимедиатехнологии». Приводится иерархическая структура работы над проектом, состоящая из пяти фаз: подготовительной, организационной, поисковоаналитической, практико-образовательной и финальной. Для каждой фазы работы над проектом создается иерархическая структура действий участников проекта. Прежде чем приступить к процессу обучения с применением проектного подхода, необходимо проводить опрос, так как анализ ответов на вопросы показывает уровень знаний, умений, владения студентов информационными технологиями, и этот факт необходимо учитывать и, как следствие, корректировать карту проекта. Карта проектного подхода при реализации дисциплины «Мультимедиатехнологии» является достаточно гибким инструментом для быстрого и наглядного внесения изменений по ходу работы. Безусловная ценность данного подхода - это учет мнения студентов и применение современных методов, методик, инструментов при реализации данной дисциплины. По итогам применения проектного подхода также составляется и проводится опрос с целью рефлексии и внесения коррективов в карту проекта для дальнейшей работы. Использование проектного подхода придает особенности самой форме реализации дисциплины «Мультимедиатехнологии» и, как следствие, развивает у студентов самостоятельность, способствует получению и актуализации знаний для решения поставленных задач.
\end{abstract}

Ключевые слова: проектный подход, проект, проектная деятельность, мультимедиатехнологии, образовательный процесс, высшее образование

\title{
APPLICATION OF THE PROJECT APPROACH IN THE IMPLEMENTATION OF THE EDUCATIONAL DISCIPLINE «MULTIMEDIATECHNOLOGIES»
}

${ }^{1}$ Sobolevskaya E.Y., ${ }^{2}$ Levchenko N.G.

${ }^{1}$ Vladivostok State University of Economics and Service, Vladivostok, e-mail: study_z@list.ru; ${ }^{2}$ Maritime State University adm. G.I. Nevelskogo, Vladivostok, e-mail: levchenko@msub.ru

The article discusses the application of the project approach as the dominant learning strategy in the implementation of the educational discipline «MultimediaTechnologies». The hierarchical structure of the work on the project is given, consisting of five phases: preparatory, organizational, search and analytical, practical and educational and final. For each phase of work on the project, a hierarchical structure of project participants' actions is developed. Before starting the learning process using the project approach, it is necessary to create and conduct a survey, since the analysis of the answers to the questions shows how much students ' knowledge, skills, and abilities are changing, and this fact must be taken into account and, as a result, adjust the project map. The map of the project approach in the implementation of the discipline «MultimediaTechnologies» is a fairly flexible tool for quick and visual changes in the course of work. The absolute value of this approach is taking students' opinions into account and the use of modern methods, techniques, tools in the implementation of this discipline. Based on the results of the project approach, a survey is also created and conducted in order to develop feedback and make adjustments to the project map for further work. The application of the project approach introduces its own features into the very form of the implementation of the discipline «Multimedia technologies», and as a result, develops students independence, obtaining and updating knowledge to solve the tasks set.

Keywords: project approach, project, project activity, multimedia technologies, educational process, higher education

Проектный подход, управление проектом повсеместно и прочно обосновались в образовательном процессе. Проектный подход предоставляет возможность студенту самостоятельно формулировать постановку целей и задач, проводить обзор и анализ информации, выбирать средства реализации для получения результата. Участие в реальных проектах при реализации дисциплины «Мультимедиатехнологии» поможет подготовить студента к будущей профессиональной деятель- ности как самостоятельного квалифицированного специалиста. Преподаватель в процессе реализации данного подхода выступает в роли наставника, не диктует свое видение реализации проекта, а только задает вектор.

Цифровизация плотно вошла во многие сферы жизнедеятельности и связана с информационными технологиями. Поэтому и значительное количество современных профессий не обходится без применения информационных технологий. Следова- 
тельно, в современном образовательном процессе необходимо увеличивать количество времени на развитие профессионально ориентированных дисциплин с использованием современных информационных технологий, способствующих креативному мышлению, систематизации полученных знаний и навыков, получению опыта творческой и исследовательский деятельности, формированию умения применять полученные теоретические знания на практике, развитию самоорганизации и ответственности, приобретению навыков работы с реальными проектами, что становится возможным при внедрении проектного подхода при реализации образовательной дисциплины «Мультимедиатехнологии».

Существует много примеров, подтверждающих необходимость разработки и развития мультимедийных продуктов [1-3]. Полученные знания в результате освоения дисциплины «Мультимедиатехнологии» позволяют в учебной, а затем и профессиональной деятельности разрабатывать мультимедийные продукты.

Целями проектного подхода при реализации образовательной дисциплины «Мультимедиатехнологии» являются повышение эффективности процесса приобретения обучающимися знаний, умений, навыков и применение их для решения поставленных задач в будущем. К тому же результат освоения дисциплины подразумевает использование многообразия информационных инструментов и технологий при разработке составляющих частей мультимедийного продукта, таких как графика, видео, аудио, гипертекст, текст и иное, что требует группового участия. Также у студентов участников проекта может быть разный уровень теоретических знаний и практических навыков.

\section{Материалы и методы исследования}

Проектный подход в современных условиях обнаруживает универсальный характер: прослеживается соединение исследовательского и прогностического, информационно-образовательного и социально-преобразовательного начал, что позволяет говорить о провозглашении проектного подхода в качестве основы образовательной парадигмы XXI в. [4]. В.Ф. Аитов, Ю.В. Еремин определяют проектный подход как реализацию ведущей, доминирующей стратегии обучения, служащей основой организации процесса образования, в котором все участники, являясь субъектами познавательного процесса, совершают самостоятельный целенаправленный, продуктивный поиск, переработку и актуализацию знаний [4].
Проектный подход в комплексе с мультимедийными технологиями в процессе формирования профессиональных компетенций обучающихся, способствуя профессиональному и личностному развитию студента, является основой для создания результата проектной деятельности, выраженного в виде конкретного мультимедийного продукта или модели. При этом созданию конечного результата проектной деятельности с применением мультимедийных технологий будут сопутствовать такие особенности, как интерактивное взаимодействие участников проекта, оперативный обмен информацией, гибкое управление проектной деятельностью, обобщение и яркая визуализация информации в одном контенте.

Очень важно и то, что проектный подход в данном случае способствует также развитию критического мышления как совокупности умений и способностей к аналитической, критической, самостоятельной умственной деятельности [5].

Проектный подход обеспечивает развитие навыков командной работы, самостоятельного принятия решений, развивает лидерские качества, что является необходимым в будущей профессиональной деятельности.

Для понимания, организации и применения проектного подхода при реализации образовательной дисциплины «Мультимедиатехнологии» была разработана иерархическая структура работы над проектом, состоящая из пяти фаз: подготовительной, организационной, поисково-аналитической, практико-образовательной и финальной (рис. 1).

Иерархическая структура наглядно показывает, какие фазы работы над проектом необходимо проработать преподавателю, каким образом организовать и контролировать рабочие и учебные процессы в каждой группе студентов, правильно расставить вехи для эффективного управления проектным процессом. Так как учебный процесс связан с учебным планом, в начале семестра данная иерархическая структура дополняется календарными датами.

Необходимо осознавать, что стейкхолдер может состоять из множества различных участников, но в большинстве своем студенческие проекты не связаны с внешними заказами на проектирование, поэтому основные участники проекта - преподаватель и группа студентов. На рис. 2 представлена иерархическая структура действий преподавателя и группы студентов на каждой фазе проекта. 

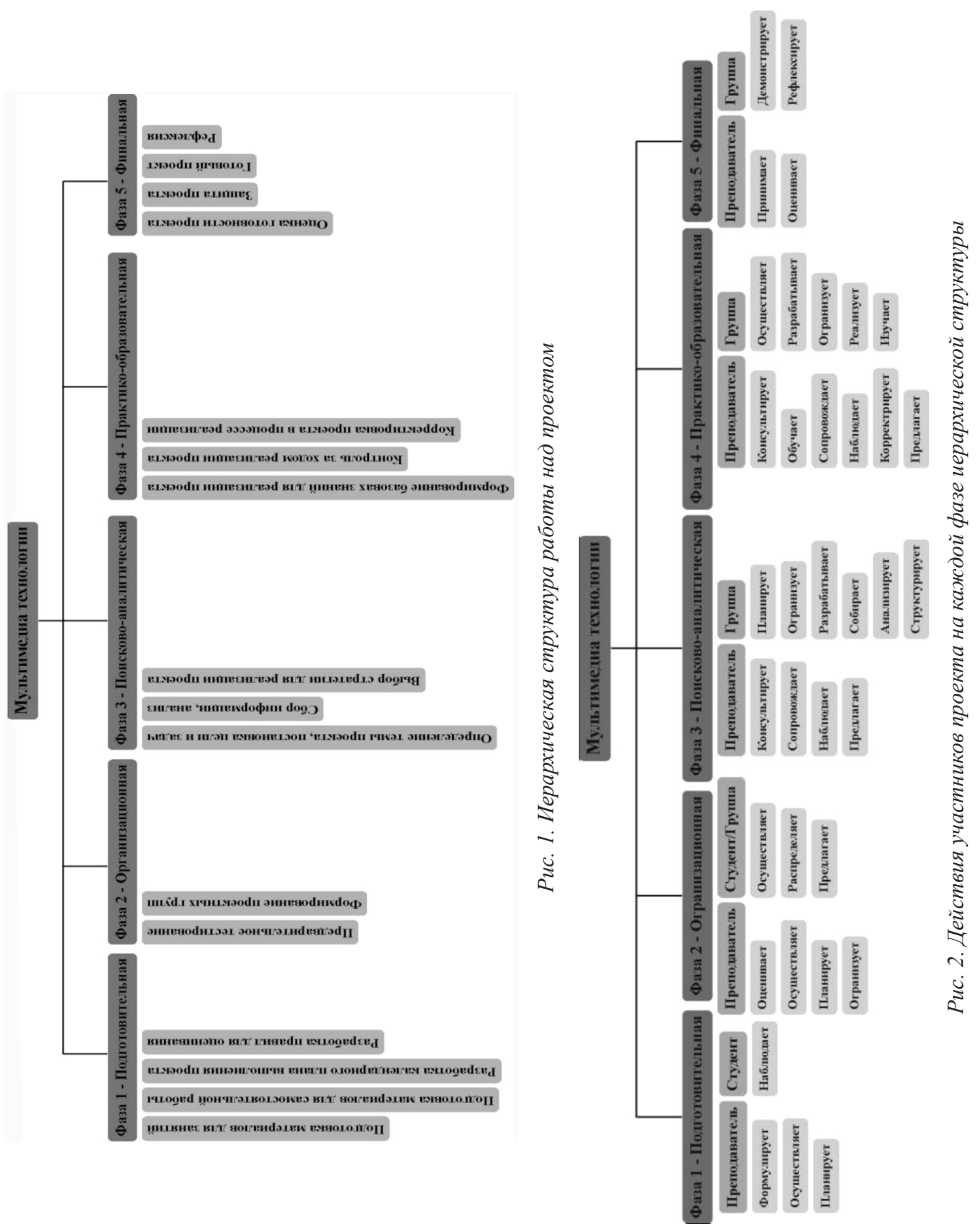
Например, на подготовительной фазе преподаватель формулирует задачу, осуществляет предварительное заполнение паспорта проекта, планирует сроки реализации и т.д. В финальной фазе преподаватель принимает реализованный группой студентов мультимедийный продукт и оценивает его. Группа студентов, в свою очередь, демонстрирует готовый мультимедийный продукт и дает обратную связь - свою оценку прохождения этапов реализации и предложения по модернизации проекта.

Также эта структура наглядно дает представление, на каком этапе реализуется работа обучающегося/студента, и помогает осуществлять контроль результата на каждом этапе проекта.

Реалии таковы, что проектная работа не всегда является продуктовым результатом для конкретного заказчика, в основном стейкхолдер включает преподавателя и обучающегося/студента. Но на самом деле, если результат получен, продукт или модель успешно реализованы, то это является немаловажным стимулом процесса обучения, даже если отсутствует конкретный внешний заказчик.

Для понимания, что и как видят участники проектной деятельности и чему необходимо обучить студента для реализации проекта в рамках дисциплины «Мультимедиатехнологии», была составлена анкета и проведен опрос, вопросы и ответы представлены на рис. 3 .

Ответы на вопросы говорят о том, что первый, второй, третий курс представлены почти поровну, четвертый курс - по минимуму. Почти у половины респондентов имелся опыт разработки мультимедийного продукта. У большинства обучающихся отсутствует опыт командной работы, но они не считают оптимальным вариант работы в группе численностью более 5 человек. Большинство опрошенных предпочитают разрабатывать игровое мобильное приложение. Обучающиеся понимают, какие именно знания и навыки им необходимы, но не совсем хорошо ориентируются в технологиях разработки мультимедийного продукта. Студенты предпочитают новые образовательные технологии классическомуподходу в обучении.

Результаты опроса позволяют составить карту реализации проекта с учетом мнения студентов. Данный опрос проводится и будет проводиться каждый раз перед началом реализации проектного подхода для данной дисциплины, так как знания, умения, владения студентов меняются, и этот факт необходимо учитывать и, как следствие, корректировать карту проекта. Фрагмент карты проектного подхода при реализации дисциплины «Мультимедиатехнологии» представлен в таблице.

Фрагмент карты проектного подхода при реализации дисциплины «Мультимедиатехнологии»

\begin{tabular}{|c|c|c|c|c|}
\hline Неделя & $\begin{array}{c}\text { Фаза - Задачи } \\
\text { (этапы) }\end{array}$ & $\begin{array}{c}\text { Метод/ } \\
\text { инструмент }\end{array}$ & Ход работы & $\begin{array}{c}\text { Необходимые } \\
\text { материалы }\end{array}$ \\
\hline 3 & $\begin{array}{l}\text { Фаза } 3 \text { - этап } \\
\text { определения } \\
\text { темы проекта, } \\
\text { п о с т а н о в к и } \\
\text { цели и задач }\end{array}$ & $\begin{array}{l}\text { Онлайн-ресур- } \\
\text { сы; речь препо- } \\
\text { давателя; работа } \\
\text { в командах (с эле- } \\
\text { ментами фасили- } \\
\text { тации) }\end{array}$ & $\begin{array}{l}\text { Разминка: преподаватель предла- } \\
\text { гает темы проекта, рассказывает } \\
\text { о каждой предметной области } \\
\text { и предлагает студентам на листке } \\
\text { записать цели и задачи. } \\
\text { Студенты сканируют QR-code } \\
\text { и переходят на онлайн-ресурс } \\
\text { google jamboard, выбирают тему } \\
\text { проекта, дополняют целью и за- } \\
\text { дачами. } \\
\text { Студенты разбиваются на группы } \\
\text { по двум-трем совпадениям выбо- } \\
\text { ра темы проекта. } \\
\text { Задание: на открытых ресурсах } \\
\text { найти информацию по теме про- } \\
\text { екта. Студенты договариваются } \\
\text { о том, кто из участников группы } \\
\text { будет сообщать результаты ко- } \\
\text { мандной работы (представлять } \\
\text { результат) }\end{array}$ & $\begin{array}{l}\text { Презентация, мульти- } \\
\text { медиаоборудование, } \\
\text { доступ в Интернет, пер- } \\
\text { сональные гаджеты сту- } \\
\text { дентов, аудитория }\end{array}$ \\
\hline
\end{tabular}



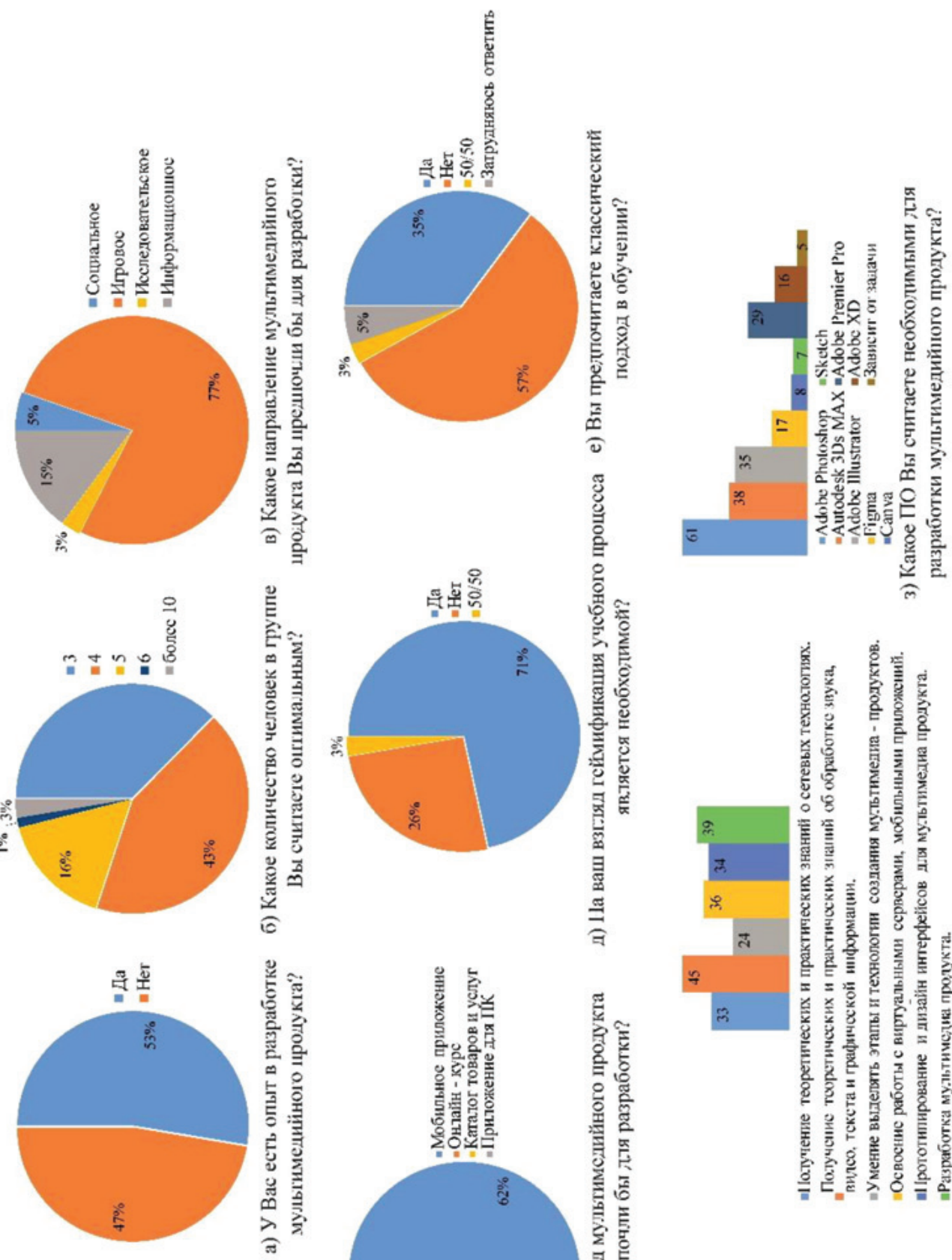

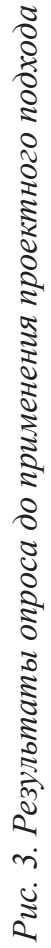




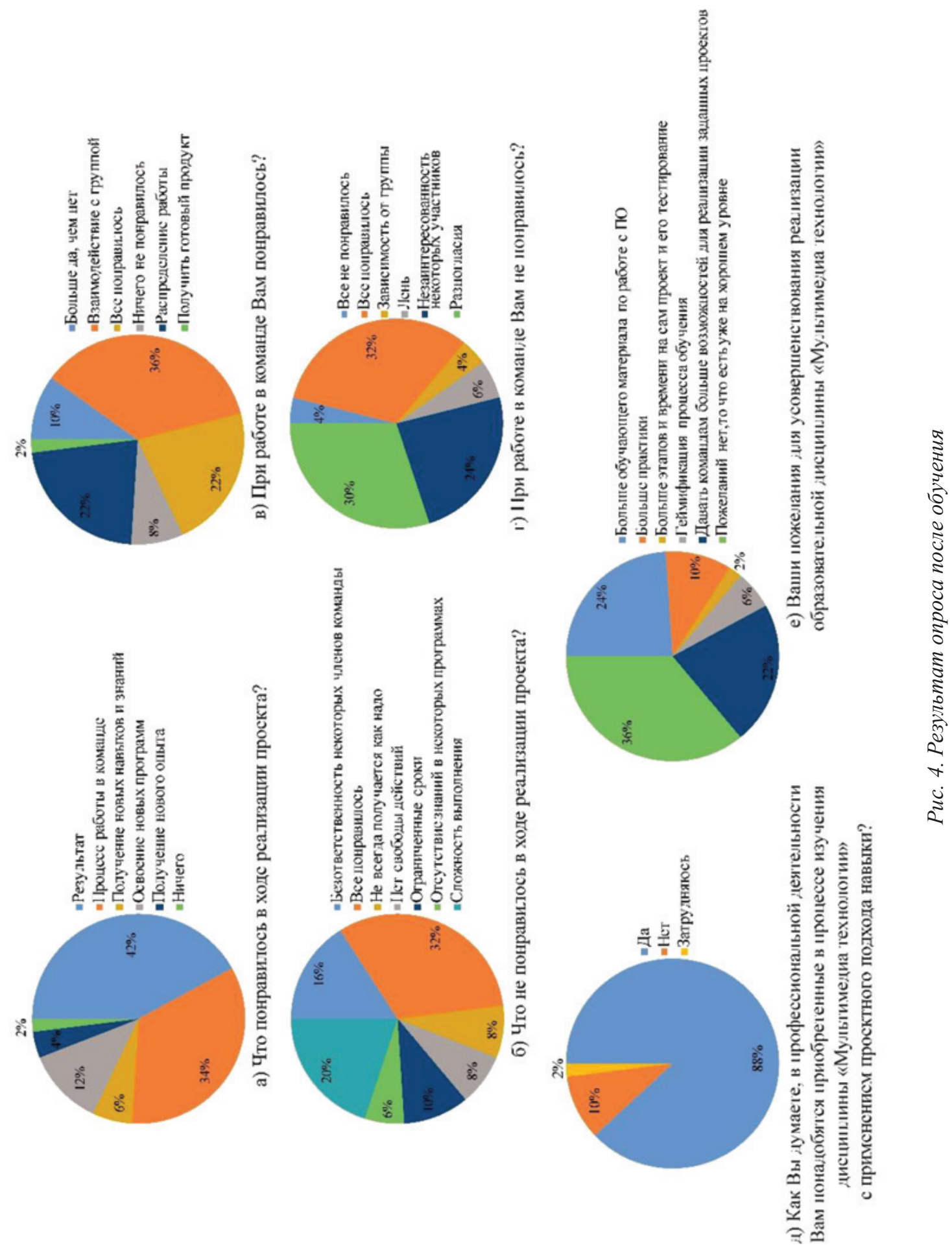


Карта проектного подхода, фрагмент которой представлен в таблице, как обобщенная структура процесса его реализации является достаточно гибким инструментом для быстрого и наглядного внесения изменений по ходу работы. Безусловная ценность данного подхода - это учет мнения студентов и применение современных методов, методик, инструментов при реализации данной дисциплины. Мнение студентов необходимо учитывать, чтобы им было интересно работать над проектом. Конечно, кому-то придется выйти из зоны комфорта и работать в группах, но это необходимый навык для работы в реальной производственной сфере/бизнесе.

По итогам применения проектного подхода был проведен опрос студентов с 1-го по 4-й курс бакалавриата основной образовательной программы 09.03.01 Информатика и вычислительная техника, которые принимали непосредственное участие в процессе обучения. Опрос проводился с целью отработки рефлексии и с целью внести коррективы в дальнейшую работу с применением проектного подхода в рамках дисциплины «Мультимедиатехнологии». На рис. 4 представлены наиболее значимые вопросы и результат.

Анализ результатов опроса после обучения позволяет увидеть и учесть недочеты при реализации дисциплины «Мультимедиатехнологии» с применением проектного подхода следующему курсу. Анализ ответов на вопросы, которые направлены на отработку рефлексии, ясно дает понять, что студентам понравилось и что не понравилось. В ходе реализации проектного подхода при изучении дисциплины «Мультимедиатехнологии», работая совместно в команде, несмотря на сложность задания, наличие разногласий в команде, они не только приобретают новый опыт, новые знания и навыки, осваивают новые информационные технологии и программное обеспечение, но и разрабатывают конкретный мультимедийный продукт. Ответы на вопросы, которые относятся к применению полученных компетенций в будущей профессиональной деятельности и выражению пожеланий по усовершенствованию реализации образовательной дисциплины «Мультимедиатехнологии», показывают одобрение респондентами проектного подхода и уверенность в необходимости приобретенных компетенций.

\section{Выводы}

Применение проектного подхода при реализации дисциплины «Мультимедиатехнологии» придает особенности самой форме организации учебного процесca, значительно ее обогащая. Изменения затрагивают и роль преподавателя, и роль обучающегося. Появляются новые образовательные технологии, которые позволяют эффективно реализовать образовательную деятельность, тем более что в процессе освоения дисциплины разрабатывается продуктовый результат, а именно готовый мультимедийный продукт, что оказывает существенное влияние на повышение интереса у студентов к самой дисциплине, к изучаемым технологиям и инструментам. Также проектная деятельность способствует формированию навыков командной работы и в то же время содействует развитию личностных качеств каждого из участников проектной деятельности.

\section{Список литературы}

1. Везиров Т.Т. Реализация проекта «мультимедийная лаборатория образовательных ресурсов» как инновационная технология в вузе // Мир науки, культуры, образования. 2018. № 6 (73). С. 44-47.

2. Сериков А.А. Особенности преподавания дисциплины «мультимедийные технологии» студентам специальности социально-культурная деятельность по виду организация и постановка культурно-массовых мероприятий и театрализованных представлений // Инновационная деятельность профессиональных образовательных организаций. 2020. № 6. С. 37-44.

3. Можарова А.Э. Мультимедийный проект как средство формирования креативной составляющей профессиональной компетентности будущего педагога // Информационно-коммуникационные технологии в педагогическом образовании. 2016. № 1(39). С. 330-343.

4. Сорокина Е.В., Турсина М.Н. Проектный подход как стратегия организации образовательного процесca. [Электронный ресурc]. URL: http://www.tsutmb.ru/nayk/ nauchnyie meropriyatiya/int konf/vseross/professionalno lichnostnoe_razvitie_prepodavatelya_i_studenta tradiczii, problemyi,_perspektivyi2/sekcziya_2/proektnyij_podxod_kak_strategiya_organizaczii_obrazovatelnogo_proczessa (дата обращения: 09.08.2021).

5. Мусина-Мазнова Г.Х., Сколота 3.Н. Технология развития критического мышления в формировании профессиональных компетенций студентов // Мир науки. 2018. Т. 6. № 6. C. 46 . 